Presentación 



\section{Presentación Anuario de Derechos Humanos 2007}

El Centro de Derechos Humanos de la Facultad de Derecho de la Universidad de Chile se complace en presentar el Anuario de Derechos Humanos 2007, tercer número de una publicación anual destinada al análisis y comentarios sobre desarrollos doctrinarios, legales y jurisprudenciales en el área de derechos humanos y materias afines, que han tenido lugar en el año precedente en el plano local e internacional.

Como es habitual, esta publicación abre con una sección de doctrina que contiene dos artículos encargados a connotados autores, sobre temas de actual y especial relevancia escogidos por el Comité Editorial del Anuario. En su número inicial, de 2005, esta sección fue dedicada a los dilemas éticos, legales y políticos que plantea la llamada lucha contra el terrorismo. En el Anuario 2006, se incluyeron sendos artículos que abordaron estrategias jurídicamente sólidas para garantizar la efectiva observancia y satisfacción del elenco de los derechos económicos, sociales y culturales. En esta oportunidad, los artículos de doctrina se centran en el análisis de los alcances del principio de igualdad y no discriminación, cuya inobservancia constituye una práctica radicalmente contraria a la noción de los derechos humanos fundados en el principio central de la igual dignidad y derechos de toda persona. Aun cuando se han conseguido avances normativos importantes en contra de la discriminación, tanto en el derecho internacional como en el orden jurídico de numerosos países, ésta subsiste en gran parte de las sociedades contemporáneas bajo formas más abiertas o más insidiosas, afectando gravemente los derechos fundamentales de diversos colectivos de personas así como la calidad democrática de los respectivos sistemas políticos y sociales. En el trabajo titulado "El Principio de Igualdad y No Discriminación. Claroscuros de la Jurisprudencia Interamericana", Ariel Dulitzky, abogado principal de la Comisión Interamericana de Derechos Humanos y reconocido experto en esta materia, analiza críticamente el desarrollo que ha tenido el principio de igualdad y no discriminación en la jurisprudencia de la Comisión Interamericana de Derechos Humanos y de la Corte Interamericana de Derechos Humanos, así como las consecuencias y obligaciones que se desprenden de una correcta aplicación de este principio para los organismos internacionales y los Estados. Por su parte, la distinguida jurista y consultora en materia de derechos de los pueblos indígenas, Silvina Ramírez, ha escrito un artículo titulado "Igualdad como Emancipación: Los Derechos Fundamentales de los Pueblos Indígenas", mediante el cual se estudian los límites de los enfoques clásicos iusfilosóficos frente al abordaje y superación de la acentuada desigualdad y exclusión que sufren diferentes colectivos indígenas en América Latina.

Siguiendo el precedente del Anuario de 2006, en esta oportunidad también se incluye un simposio especial, el cual está dedicado a una "Revisión Crítica del Sistema Interamericano de Derechos Humanos". Luego de varias décadas de funcionamiento, dicho sistema, constituido principalmente por la Comisión Interamericana de Derechos Humanos y la Corte Interamericana de Derechos Humanos y cuyo funcionamiento requiere de la participación activa de Estados, peticionarios y organizaciones de la sociedad civil del hemisferio, ha realizado importantes y crecientes contribuciones a la creación de una conciencia regional sobre esta temática, al desarrollo de relevante 
doctrina y jurisprudencia, a la protección de los derechos humanos de numerosas personas y grupos y a la introducción de significativas reformas legales, institucionales y de políticas públicas en diversos países de América. Con todo, el sistema acusa diversas insuficiencias y ha sido objeto también de serias críticas. Este simposio pretende entregar una reflexión sucinta pero profunda sobre el pasado, presente y futuro del Sistema Interamericano. Con ese fin, once personas expertas contestaron un mismo conjunto de preguntas. Los participantes son hombres y mujeres que cumplen o han cumplido altas funciones de Estado en materia de derechos humanos (Paulo Vannuchi -Brasil- y Juan José Gómez Camacho -México-); han servido en la Comisión Interamericana (Claudio Grossman y Robert Goldman, quienes escriben conjuntamente con Claudia Martin y Diego Rodríguez Pinzón -profesores del Washington College of Law-) o en la Corte Interamericana (Pedro Nikken); tienen experiencia en el tema por sus funciones directivas en organizaciones no gubernamentales nacionales (Gustavo Gallón y Luz Marina Monzón -quienes participaron en forma conjunta como miembros de la Comisión Colombiana de Juristas-) o regionales (Viviana Krsticevic, de CEJIL); o son académicas de reconocida trayectoria en el campo (Mónica Pinto).

El Anuario 2007 cuenta, asimismo, con sus secciones habituales de comentarios de importantes fallos, legislación y otros desarrollos, nacionales e internacionales, que tuvieron lugar en el año precedente. Estos artículos son de autoría de expertos y expertas invitados (Diego Camaño Viera, de Uruguay; Soledad Pujó y Malena Derdoy, de Argentina; Morton Halperin y Diane Orentlicher, de Estados Unidos; Eduardo González Cueva, de Perú; y Sofía Correa Sutil y Pablo Ruiz-Tagle, de nuestra propia Facultad de Derecho) y de integrantes del Centro de Derechos Humanos (Mariano Fernández Valle, Alex Muñoz Wilson, Claudio Nash y Claudia Sarmiento -quienes contribuyeron en forma conjunta-, y Verónica Undurraga Valdés, además de los suscritos).

La sección de temas emergentes del Anuario 2007 está dedicada a "Derechos Humanos y Migraciones", tema que si bien no es estrictamente nuevo, es poco conocido en nuestro medio y revela diferentes desarrollos normativos, institucionales y políticos, a la vez que motiva una creciente ocupación por parte de los Estados y de los organismos de control locales e internacionales. Sobre esta materia ha escrito Helena Olea Rodríguez, quien estuvo vinculada con nuestro Centro durante el año 2006.

Con el objeto de lograr una mayor difusión de este Anuario, el Centro de Derechos Humanos lo publica en forma impresa y, paralelamente, en formato digital en la página www.anuariocdh.uchile. cl. Esta modalidad de difusión ha sido posible por el apoyo en el diseño y creación de este sitio web brindado por los profesionales de SISIB de la Universidad de Chile, a quienes agradecemos sinceramente su colaboración.

Junto con extender nuestros agradecimientos a los autores y las autoras de los artículos y comentarios incluidos en este Anuario, expresamos también nuestra gratitud a las instituciones donantes que con sus aportes hacen posible el financiamiento de los distintos programas del Centro: el Estado de Chile, la Fundación Ford, el Ministerio de Relaciones Exteriores de Noruega, el Open Society Institute, UNIFEM, ACNUR y las fundaciones Sigrid Rausing Trust, John Merck y Overbrook.

En esta ocasión cumplimos con el grato deber de agradecer especialmente a Mariano Fernández Valle, jurista argentino que forma parte del staff de nuestro Centro, quien ha tenido como editor de este Anuario la responsabilidad principal en su coordinación y producción.

Confiamos en que el Anuario 2007 sea de utilidad para contribuir al progreso y garantía de los derechos humanos $y$, consecuentemente, para el fortalecimiento de la democracia y el estado de derecho.

Cecilia Medina Q.

Co-Directora
José Zalaquett D.

Co-Director 